\title{
Numerical Simulations of Spread Characteristics of Toxic Cyanide in the Danjiangkou Reservoir in China under the Effects of Dam Cooperation
}

\author{
Libin Chen, Zhifeng Yang, and Haifei Liu \\ State Key Laboratory of Water Environment Simulation, School of Environment, Beijing Normal University, Beijing 100875, China \\ Correspondence should be addressed to Zhifeng Yang; zfyang@bnu.edu.cn
}

Received 16 June 2014; Revised 1 September 2014; Accepted 1 September 2014; Published 29 September 2014

Academic Editor: Ricardo Aguilar-López

Copyright @ 2014 Libin Chen et al. This is an open access article distributed under the Creative Commons Attribution License, which permits unrestricted use, distribution, and reproduction in any medium, provided the original work is properly cited.

\begin{abstract}
Many accidents of releasing toxic pollutants into surface water happen each year in the world. It is believed that dam cooperation can affect flow field in reservoir and then can be applied to avoiding and reducing spread speed of toxic pollutants to drinking water intake mouth. However, few studies investigated the effects of dam cooperation on the spread characteristics of toxic pollutants in reservoir, especially the source reservoir for water diversion with more than one dam. The Danjiangkou Reservoir is the source reservoir of the China' South-to-North Water Diversion Middle Route Project. The human activities are active within this reservoir basin and cyanide-releasing accident once happened in upstream inflow. In order to simulate the spread characteristics of cyanide in the reservoir in the condition of dam cooperation, a three-dimensional water quality model based on the Environmental Fluid Dynamics Code (EFDC) has been built and put into practice. The results indicated that cooperation of two dams of the Danjiangkou Reservoir could be applied to avoiding and reducing the spread speed of toxic cyanide in the reservoir directing to the water intake mouth for water diversions.
\end{abstract}

\section{Introduction}

Many accidents of releasing toxic pollutants into surface water happen each year in the world. For example, 1250 tons of toxic pollutants such as sulfur, phosphorous, and mercury flowed into Rhine River along with hydrating water after sudden explode of Sandoz Laboratory on November 1, 1986, in Basel Warehouse, Switzerland. This accident led fishes and other species within range of $160 \mathrm{~km}$ of the river to death in one night and the drinking water all polluted [1]. $100,000 \mathrm{~m}^{3}$ cyanide and heavy metals were accidentally released from a retaining wall at the Aurul gold processing plant in Romania on January 30, 2000, the cyanide and heavy metals moved quickly from one river to the next, killing fish and other wildlife, as well as poisoning drinking water [2]. On November 13, 2005, 100 tons of toxic aniline and related compounds was accidentally released into the Songhua River of China, which greatly threated the safety of drinking water in downstream [3].
Accidental release of toxic pollutants into surface water would threat the safety of drinking water resource and human health tremendously $[4,5]$. Many water pollution emergency response systems based on water quality modeling and GIS technology have been developed including the Spill Management Information System (SMIS) for inland waterway that coupled with GIS and database management systems with the $2 \mathrm{D}$ surface water quality model CE-QUAL-W2 [6, 7], the water pollution emergency response system for the Three Gorges Reservoir (WPMS_ER_TGRA) that coupled with GIS and database management systems with $1 \mathrm{D}$ and $2 \mathrm{D}$ dynamic hydraulic/water-quality mathematical models [8], the GIS-based generic real-time risk assessment framework and decision tools for chemical spills in the river basin [9], and the conceptual GIS-SD framework that couples GIS and 1D water quality model simulating the temporalspatial changes of pollutant concentration [10], as well as the RiverSpill system for streams and rivers that are based on GIS and water quality mode [11]. 
The systems discussed above have successfully tracked pollutants in the surface waters. However, few studies have involved in scenario analysis and mitigation management on accidental release of toxic pollutants spreading to the drinking water intake mouth in reservoir based on dam operation [12]. As to our knowledge, there is no research that studied the effects of multiple-dam cooperation on the spread characteristics of toxic pollutants in reservoir. It is believed that the multiple-dam cooperation can change flow field in the reservoir and then can be used to avoid and reduce spread speed of toxic pollutants to the water intake mouth, especially in a source reservoir for water diversion.

The Danjiangkou Reservoir is the source reservoir of China's South-to-North Water Diversion Middle Route Project (S-N-M Project). The water quality in this reservoir determines the fate of local ecosystem, human health in the receipt area (e.g., Beijing city and Tianjin city), and downstream of the great Danjiangkou Dam (e.g., Xiangfan City and Wuhan City). Unfortunately, human activities are active in this reservoir basin and toxic pollutants accidental release issue once happened in upstream inflow of this reservoir. For instance, 5.2 tons of toxic sodium cyanide was accidentally released into a tributary of the Han River (main tributary of the Danjiangkou Reservoir) in September 29 in year 2000 [13], which caused public panic. Although this accident did not cause serious damage to the water quality in the Danjiangkou Reservoir, the environmental safety consciousness has been added to the public. If similar accidents happen in the Danjiangkou Reservoir, what should we do? The Danjiangkou Reservoir has two dams: the Taocha Dam and the Danjiangkou Dam. The Taocha Dam operates for water diversion to the northern China and the Danjiangkou Dam operates for the downstream of the Han River. The cooperation of the two dams can influence the flow field in the reservoir, which can further influence the spread characteristic of toxic cyanide in the reservoir.

The objective of this study is to simulate the spread characteristics of cyanide in the Danjiangkou Reservoir based on the assumption that accidental release of cyanide into two main tributaries. The operations of the two dam including Danjiangkou Dam and Taocha Dam will be optimized to mitigate the toxic cyanide damage to the water quality for water diversion.

\section{Matters and Methods}

2.1. Study Area. The Danjiangkou Reservoir, constructed in 1958 and located at the upstream of the Han River (as shown in Figure 1), is the source reservoir of the S-N-M Project. In order to satisfy the water diversion, the Danjiangkou Dam of the reservoir has been elevated from $162 \mathrm{~m}$ to $176.6 \mathrm{~m}$ and the normal water level will be elevated from $157 \mathrm{~m}$ to $170 \mathrm{~m}$. The water surface of the reservoir will be enlarged to $1022.75 \mathrm{~km}$ and the reservoir capacity will be increased to 33.91 billion $\mathrm{m}^{3}$. The Taocha Dam is the water diversion dam, which is located at northeast of the reservoir, far away from the Danjiangkou Dam. The reservoir will transfer water to northern China from autumn of 2014 with the designed flow being $350 \mathrm{~m}^{3} / \mathrm{s}$ and the annual amount of water diversion being 9.5 billion cubic meters. The reservoir has four main tributaries: the Han River, the Guanshan River, the Lang River, and the Dan River.

2.2. Model Set-Up and Calibrations. The 3D water quality model was built based on the Environmental Fluid Dynamic Code (EFDC). The EFDC is a $3 \mathrm{D}$ software package with open source for the analysis of hydrodynamic and water quality [14]. The code has been extensively tested, documented, and applied to environmental studies [15-19]. In the EFDC, the governing equations of hydrodynamics are solved in horizontal orthogonal curvilinear or Cartesian coordinates and vertical stretched sigma coordinate. The equations related to the vertical stretching transformation, continuity, momentum, and transport equations are descripted by (1)-(10) [20]:

$$
\begin{gathered}
z=\frac{\left(z^{*}+h\right)}{(\zeta+h)} \\
\partial_{t}(m H u)+\partial_{x}\left(m_{y} H u u\right)+\partial_{y}\left(m_{x} H v u\right)+\partial_{z}(m w u) \\
-\left(m f+v \partial_{x} m_{y}-u \partial_{y} m_{x}\right) H v \\
=-m_{y} H \partial_{x}(g \zeta+p)-m_{y}\left(\partial_{x} h-z \partial_{x} H\right) \partial_{z} p \\
+\partial_{z}\left(m H^{-1} A_{v} \partial_{z} u\right)+Q_{u} \\
\partial_{t}(m H v)+\partial_{x}\left(m_{y} H u v\right)+\partial_{y}\left(m_{x} H v v\right)+\partial_{z}(m w v) \\
+\left(m f+v \partial_{x} m_{y}-u \partial_{y} m_{x}\right) H u \\
=-m_{x} H \partial_{y}(g \zeta+p)-m_{x}\left(\partial_{y} h-z \partial_{y} H\right) \partial_{z} p \\
+\partial_{z}\left(m H^{-1} A_{v} \partial_{z} v\right)+Q_{v}, \\
\partial_{z} p=-g H\left(\rho-\rho_{0}\right) \rho_{0}^{-1}=-g H b \\
\partial_{t}(m H S)+\partial_{x}\left(m_{y} H u S\right)+\partial_{y}\left(m_{x} H v S\right)+\partial_{z}(m w S) \\
\partial_{t}\left(m H^{-1} A_{b} \partial_{z} T\right)+Q_{T} \cdot \\
\partial_{t}(m \zeta)+\partial_{x}\left(m_{y} H u\right)+\partial_{y}\left(m_{x} H v\right)+\partial_{z}(m w)=0 \\
m_{y} H \int_{0}(m d z)+\partial_{y}\left(m \partial_{z} S\right)+Q_{S}, \\
v d z)=0
\end{gathered}
$$

In the above equations, $z^{*}$ indicate the original physical vertical coordinates; $h$ and $\zeta$ are the physical vertical coordinates of the bottom topography and the free surface, respectively; $u$ and $v$ are the horizontal velocity components in the curvilinear and orthogonal coordinates $x$ and $y ; m_{x}$ and $m_{y}$ are the square roots of the diagonal components of 


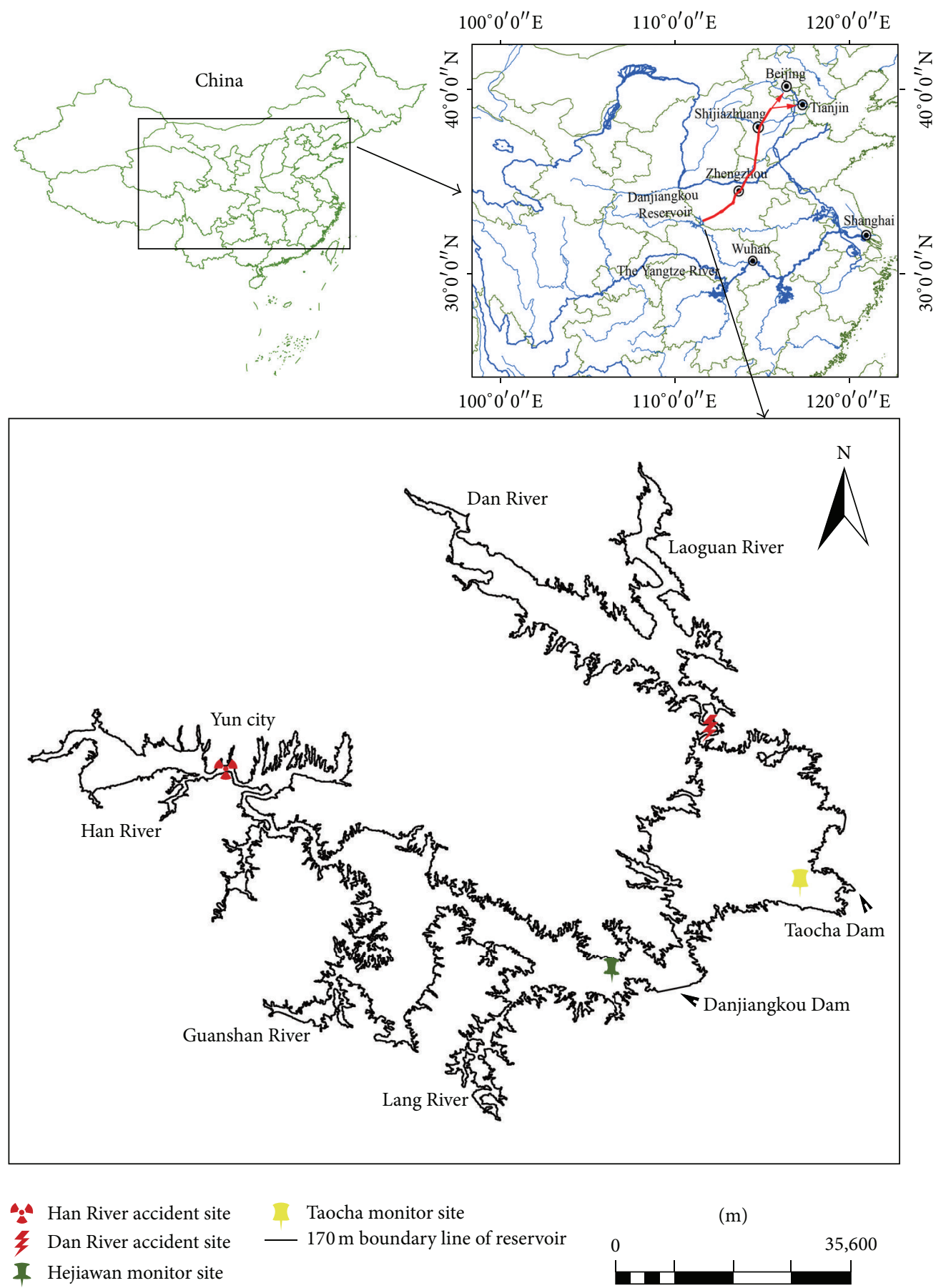

FIGURE 1: Location of the study area and the sites for accidental release of cyanide.

the metric tensor and $m=m_{x} m_{y}$ is the Jacobian (square root of the metric tensor determinant). The vertical velocity in the stretched and dimensionless vertical coordinate $z$ is $w$, and it is related to the physical vertical velocity $w^{*}$ by

$$
\begin{aligned}
w= & w^{*}-z\left(\partial_{t} \zeta+u m_{x}^{-1} \partial_{x} \zeta+v m_{y}^{-1} \partial_{y} \delta\right) \\
& +(1-z)\left(u m_{x}^{-1} \partial_{x} h+v m_{y}^{-1} \partial_{y} h\right) .
\end{aligned}
$$

The total depth, $H=h+\zeta$, is the sum of the depth below and the free surface displacement relative to the undisturbed physical vertical coordinate origin, $z^{*}=0$. The pressure $p$ is the physical pressure in excess of the reference density hydrostatic pressure, $\rho_{0} g H(1-z)$, divided by the reference density, $\rho_{0}$. In the momentum equations (2) and (3) $f$ indicate the Coriolis parameter, $A_{v}$ is the vertical turbulent (eddy viscosity), and $Q_{u}$ and $Q_{v}$ are momentum source-sink terms, which will be modeled later as subgrid-scale horizontal 

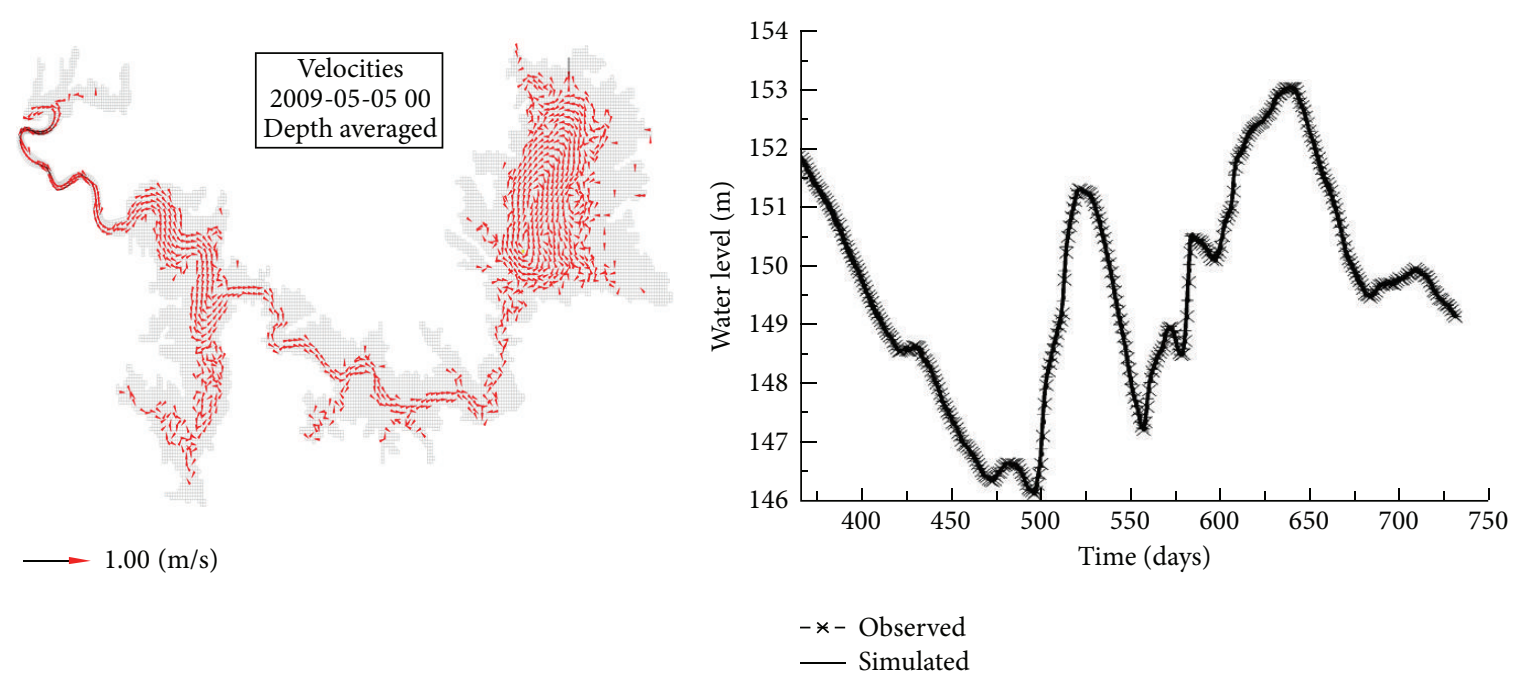

FIGURE 2: Flow field and water levels calibration for the hydrodynamic model of the Danjiangkou Reservoir.

diffusion. The buoyancy, $b$, is defined in (4) as the normalized deviation of the density from the reference value. The continuity equation (5) has been integrated with respect to $z$ over the interval $(0,1)$ to produce the depth integrated continuity equation (6) using the vertical boundary conditions $w=0$ at $w=(0,1)$, which follows from the kinematic conditions and (10). In the transport equations for salinity and temperature, (8) and (9), the source and sink terms, $Q_{S}$ and $Q_{T}$, include the subgrid-scale horizontal diffusion and thermal sources and sinks, while $A_{b}$ is the vertical turbulent diffusivity.

The governing mass-balance equation for the water quality state variable can be expressed as $[21,22]$

$$
\begin{aligned}
\partial_{t} C & +\partial_{x}(u C)+\partial_{y}(v C)+\partial_{z}(w C) \\
& =\partial_{x}\left(K_{x} \partial_{x} C\right)+\partial_{y}\left(K_{y} \partial_{y} C\right)+\partial_{z}\left(K_{z} \partial_{z} C\right)+S_{C}
\end{aligned}
$$

where $C$ is the concentration of a state variable, $u, v$, and $w$ are velocity components in the $x, y$, and $z$ directions, respectively, $K_{x}, K_{y}$, and $K_{z}$ are turbulent diffusivities in the $x, y$, and $z$ directions, respectively, and $S_{C}$ is the internal and external sources and sinks per unit volume.

The governing mass-balance equation for water quality state variables (see (11)) consists of physical transport (adjective and diffusive) and kinetic processes. When solving (11), the kinetic terms are decoupled from the physical transport terms. The mass-balance equation for physical transport only is

$$
\begin{aligned}
\partial_{t} C & +\partial_{x}(u C)+\partial_{y}(v C)+\partial_{z}(w C) \\
& =\partial_{x}\left(K_{x} \partial_{x} C\right)+\partial_{y}\left(K_{y} \partial_{y} C\right)+\partial_{z}\left(K_{z} \partial_{z} C\right) .
\end{aligned}
$$

The equation for kinetic processes only, which will be referred to as kinetic equation, is

$$
\partial_{t} C=S_{C}
$$

which is expressed as

$$
\partial_{t} C=K \cdot C+R
$$

where $K$ is kinetic rate $\left(\right.$ time $^{-1}$ ) and $R$ is source/sink term (mass volume time $^{-1}$ ). Equation (14) is obtained by linearizing some terms in the kinetic equations, Monod type expressions. Hence, $K$ and $R$ are known value in (14). Equation (12) is identical with, and thus its numerical method of solution is the same as, the mass-balance equation for salinity [14]. More detailed information about the solution method of the governing mass-balance equations can be seen in Park et al. [21].

Orthogonal and curvilinear grids were built for the water quality model of the Danjiangkou Reservoir which totally has 60000 quadrilateral grids comprising 10000 grids in the horizontal plane and 6 layers in the vertical direction. The bathymetry of the water quality model was constructed by overlaying and interpolating the DEM data of the reservoir area with the field measurement data in the reservoir. The DEM data were downloaded from the Geospatial Data Cloud (http://www.gscloud.cn/). The field data were measured using the HydroBat Compact Multibeam Sonar System. As to the calibration of the hydrodynamic part of the model, the period for calibration was from January 1, 2009, to December 31,2009 , with the initial water surface elevation being $151.9 \mathrm{~m}$. The inflow boundaries were the Han River, the Guanshan River, the Lang River, and the Dan River (see Figure 1). The outflow boundaries were the Danjiangkou Dam and the Taocha Dam. The required boundary conditions were the data of daily inflow, outflow, and atmospheric factors. The atmospheric factor data include wind speed and wind direction, which were obtained from local agencies. The water levels in the Danjiangkou Dam area and flow field in the whole reservoir were applied to calibrating the hydrodynamic model. The calibrated results can be seen in Figure 2. As the Figure 2 shows, the simulated water level was calibrated very well with the observed value and the flow field in 
TABle 1: Scenarios setting for accidental release of cyanide into the Danjiangkou Reservoir.

\begin{tabular}{lccc}
\hline Scenarios & Accident site & Outflow $\left(\mathrm{m}^{3} / \mathrm{s}\right)$ & Tanjiangkou Dam \\
\hline 1 & Dan River estuary & Reference outflow & 350 \\
2 & Dan River estuary & 0 & 350 \\
3 & Dan River estuary & Reference outflow & 0 \\
4 & Dan River estuary & 0 & 0 \\
5 & Yun City Bridge & Reference outflow & 350 \\
6 & Yun City Bridge & 0 & 350 \\
7 & Yun City Bridge & Reference outflow & 0 \\
8 & Yun City Bridge & 0 & 0 \\
\hline
\end{tabular}

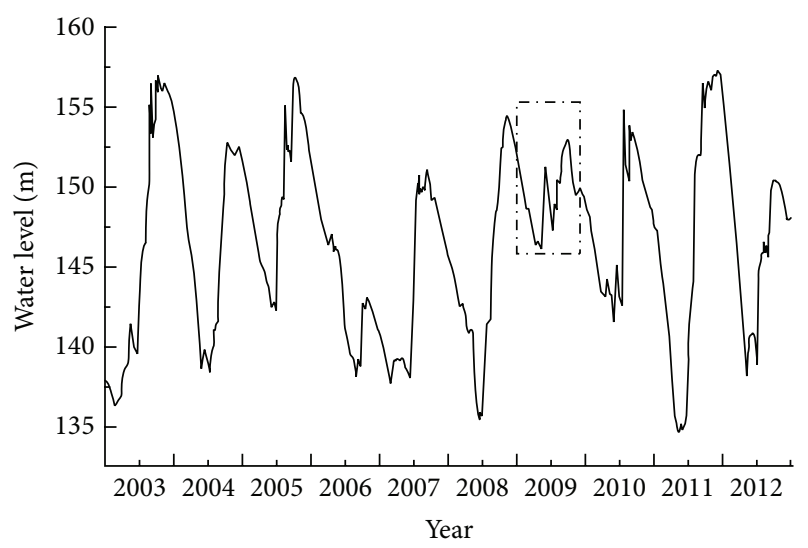

Figure 3: Daily water levels in Danjiangkou Dam area during the last 10 years.

the reservoir was also reasonable. It is indicated that the hydrodynamic model can be used to build the water quality model for simulating the spread characteristics of cyanide in the Danjiangkou Reservoir.

In the water quality module, first order degradation of the cyanide was considered. The degradation rate was obtained from the experimental testing of the degradation of the sodium cyanide in static water [23]. The decay rate was set as 0.028 /day.

2.3. Scenarios Setting. Accidental release of cyanide was supposed to occur at two sites. One was at Yun City Bridge over the Han River and another was at the Dan River (see Figure 1). In each site, 2 tons of sodium cyanide was accidentally released into the reservoir on May 5. The initial water surface was set as $155 \mathrm{~m}$. The inflow boundaries and meteorological boundaries were set as those in year 2009. The outflow boundary in the Taocha Dam was the designed outflow $\left(350 \mathrm{~m}^{3} / \mathrm{s}\right)$ of the S-N-M Project. The outflow in the Danjiangkou Dam was supposed to be the outflow in year 2009 minus $350 \mathrm{~m}^{3} / \mathrm{s}$. These outflows were set as the reference outflows for the other scenarios setting. The hydrological year of 2009 was selected as the reference hydrological year, because the lowest water level in this year was near to $150 \mathrm{~m}$ during the last 10 years (see Figure 3). This $150 \mathrm{~m}$ water level is the designed lowest water level of the Danjiangkou Reservoir, as the Danjiangkou Dam rises to $176.6 \mathrm{~m}$ and the normal water level rises to $170 \mathrm{~m}$. It is considered that the hydrological year of 2009 can present the future hydrological year for the water diversion to some extent.

In order to explore the effects of dam cooperation on the spread characteristics of cyanide in the Danjiangkou Reservoir, eight scenarios were set up. In each accident site, four scenarios were simulated. The first was normal water diversion in the Taocha Dam and normal outflow from the Danjiangkou Dam, the second was shutting down the Taocha Dam and normal outflow from the Danjiangkou Dam, the third was shutting down the Danjiangkou Dam and normal water diversion in the Taocha Dam, and the forth was shutting down the two dams. The detailed information of the scenarios setting was listed in Table 1 . Two monitor sites were set for monitoring the effects of these scenarios on the cyanide concentration in the reservoir: the Hejiawan monitor site and the Taocha monitor site (see Figure 1).

\section{Results and Discussions}

3.1. The Spread Characteristics of Accidental Release of Cyanide from the Han River. As Figure 4 depicts, in the horizontal view, the cyanide in the reservoir forms a high concentration area in the Han River estuary after 7 days since the accidental release of cyanide occurrence at the Yun City Bridge. After that time, the cyanide spread along a thin channel to the area near the Danjiangkou Dam with a relative low concentration. After 10 days, the cyanide can reach to the Danjiangkou Dam area, then, one part of the cyanide flows out of the reservoir, one part of the cyanide flows to the Dan part of the reservoir and then directs to the Taocha Dam area, the water intake mouth of the S-N-M Project. After 20 days, the high concentration of cyanide can reach the Danjiangkou Dam area, and after 90 days, the high concentration of the cyanide can be found in the Dan part of the reservoir. As the water quality in the Dan part reservoir is very important to northern China, it is suggested that the Danjiangkou Dam increase outflow rate when the cyanide approach to the Danjiangkou Dan area, to prevent the cyanide from spreading to the Dan part of the reservoir and threating to the S-N-M Project. 

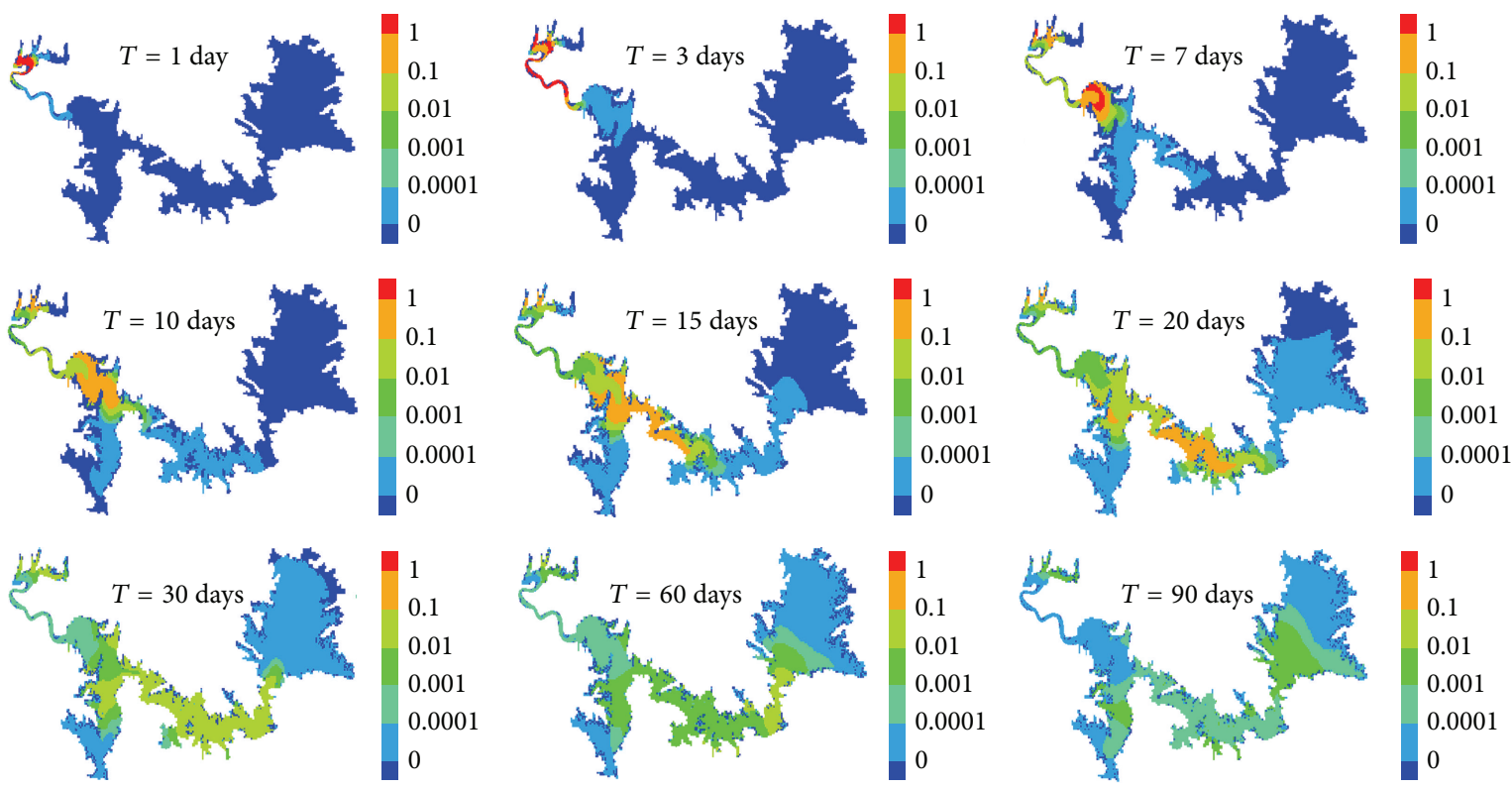

FIGURE 4: Spread characteristics of accidental release of cyanide from the Yun City Bridge in the horizontal view.
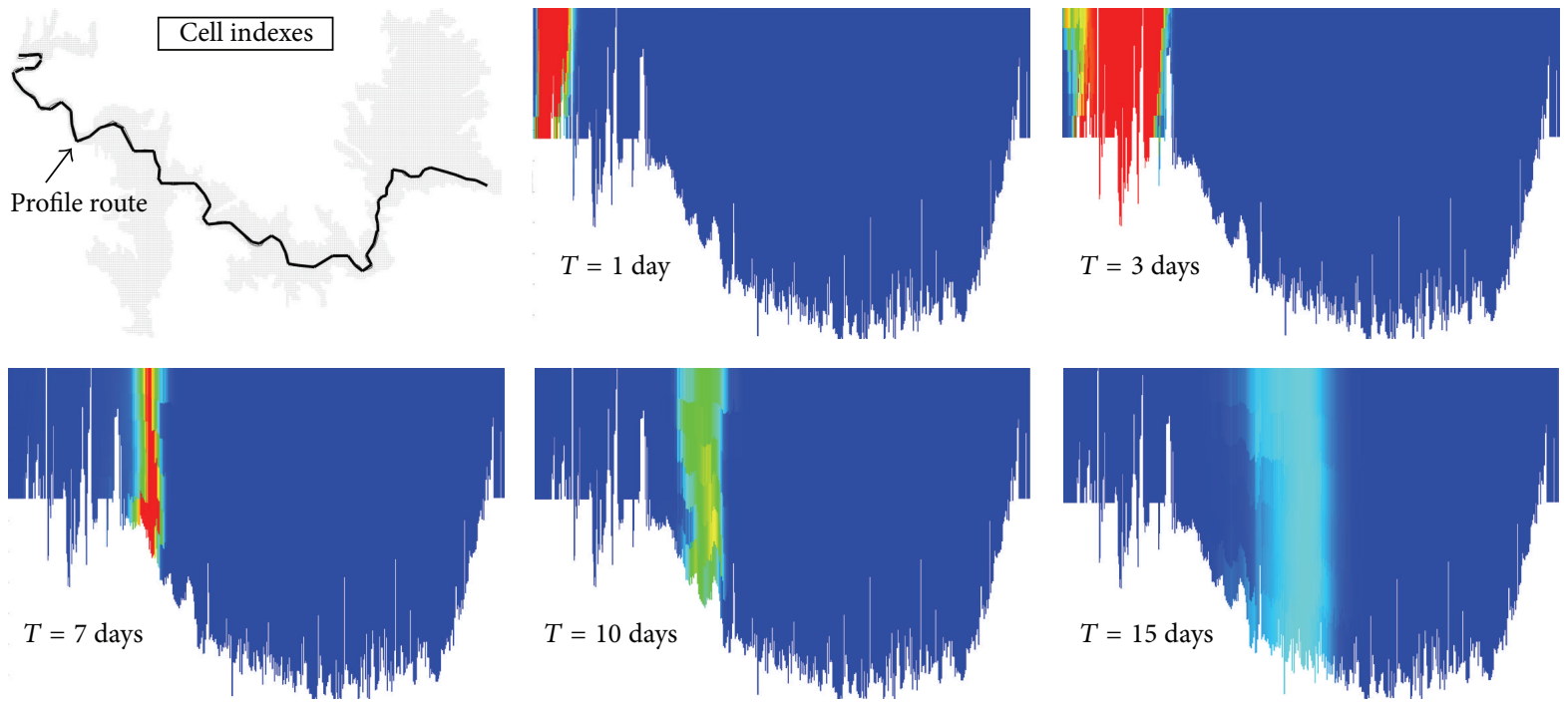

FIGURE 5: Spread characteristics of accidental release of cyanide from the Yun City Bridge in the vertical view (the concentration legend is the same as the figure of the horizontal view).

As Figure 5 shows, in the vertical view, the concentration of the cyanide in the reservoir was not obviously different since the accidental release of cyanide occurrence at the Yun City Bridge. This is possibly attributed to that the complex mixing process is dominated by inflow from the Han River which is the main inflow of the Danjiangkou Reserovir contributing $90 \%$ water to the this reservoir.

As it is presented in Figure 6, the time series of cyanide concentration at the Taocha Dam area have a peak value, on the 118 days after the accident. In this study, the peak value is far below the safety concentration of national standard (GB 5749-2006) for drinking water in China. The national standard sets the safety value of cyanide for drinking water is $0.05 \mathrm{mg} / \mathrm{L}$. It implies that the accidental release of 2 tons of cyanide in this scenario has no threat to drinking water quality for the S-N-M Project. However, due to the uncertainty amount of accidental release of cyanide, the concentration of cyanide in the reservoir would not be a safety value all the time. It depends on the amount of the cyanide, the initial water surface elevation, and inflow rate and outflow rate of the reservoir.

3.2. The Spread Characteristics of Accidental Release of Cyanide from the Dan River. As Figure 7 shows, in the horizontal view, the cyanide can spread to the Taocha Dam area, 3 days after the accidental release of cyanide at the Dan River. Then, 


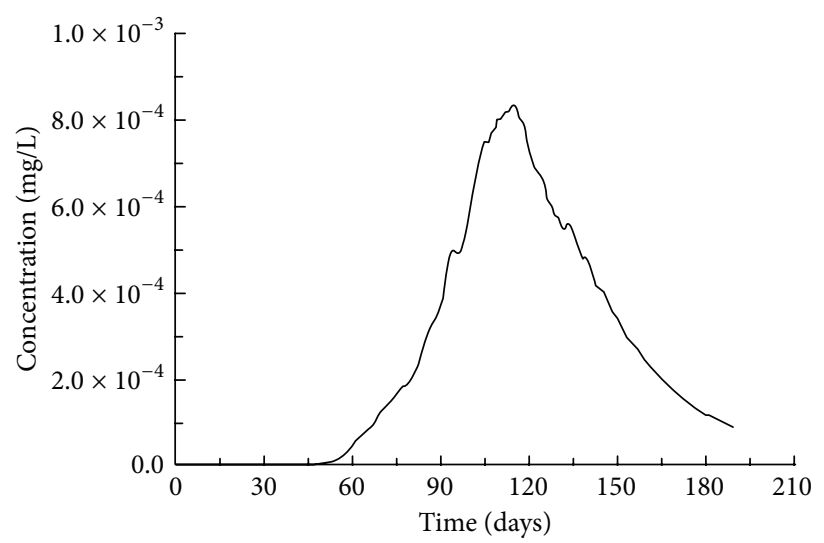

Figure 6: Time series of cyanide concentration in Taocha Dam area after accidental release of cyanide from the Yun City Bridge.
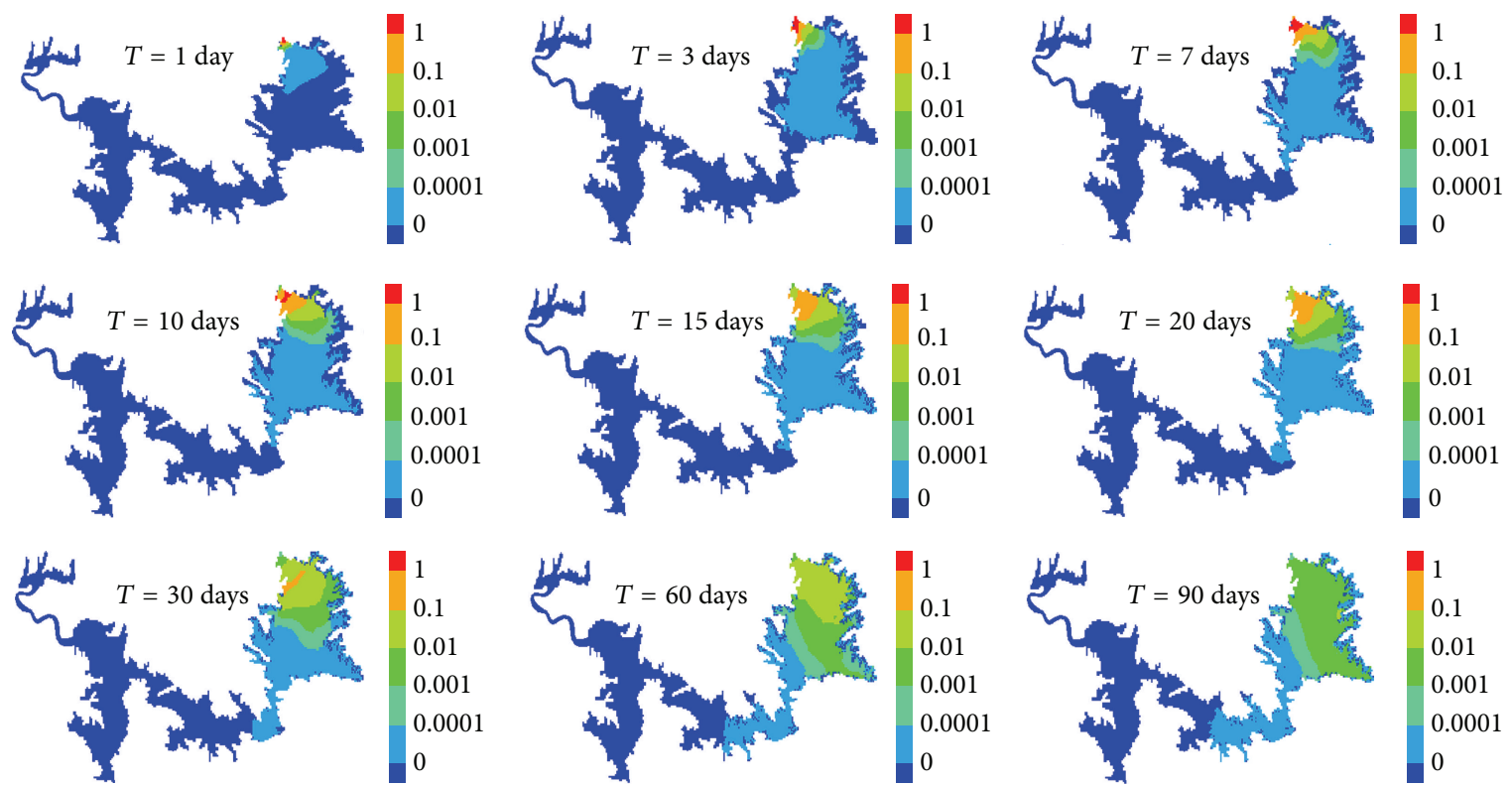

FIGURE 7: Spread characteristics of accidental release of cyanide from the Dan River in the horizontal view.

the cyanide group moved along the northeast of the reservoir and directed to the Taocha Dam area. After 90 days, the high concentration area of the cyanide located at the Taocha area. As the cyanide from Dan River was ultimately spread to the Taocha area and threat to the S-N-M Project, it is suggest that more effects should be paid to protect the Dan River and prohibit cyanide from releasing into the reservoir.

As it is presented in Figure 8, in the vertical view, the concentration of the cyanide in the reservoir was not obviously different since the accidental release of cyanide occurrence at the Dan River. This is possibly attributed to the fact that the complex mixing process is dominated by the wind stress and the cooperation of two dams.

As Figure 9 depicts, the time series of cyanide concentration at the Taocha Dam area has a peak value, 90 days after the accidental release of cyanide at the Dan River. The peak value was far below the safety concentration of the national standard (GB 5749-2006) for drinking water. It is suggested that 2 tons of cyanide released in this accident is also not a great threat to the drinking water for the S-N-M Project in the hydrological year of 2009 .

3.3. Dam Cooperation Affects the Spread Characteristics of Cyanide from the Han River. Though 2 tons of cyanide release from two main tributaries would not be a great threat to the water quality for water diversion, it is still significant to study the effects of dam cooperation on the spread characteristics of cyanide in the reservoir for the uncertain amount of cyanide in a real accidental release.

It can be seen that in Figure 10(a), shutting down dams can obviously affect the spread speed of cyanide in the reservoir. For example, shutting down the Danjiangkou Dam can obviously reduce the peak concentration of cyanide at the Hejiawan monitor site. It postponed 7 days that the peak concentration of cyanide to the Hejiawan monitor site, which gives more time to carry out emergency measures for 

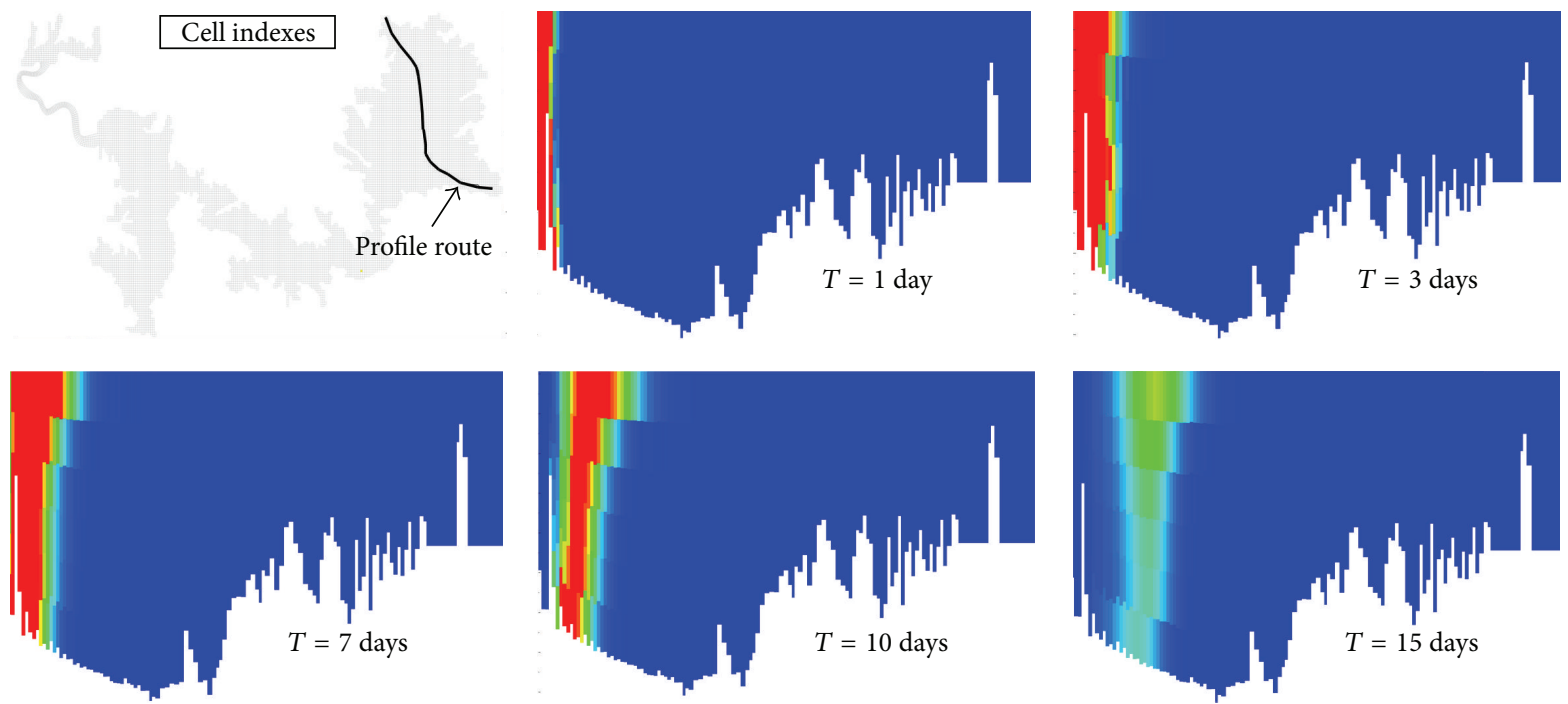

FIGURE 8: Spread characteristics of accidental release of cyanide from the Dan River in the vertical view (the concentration legend is the same as the figure of horizontal view).

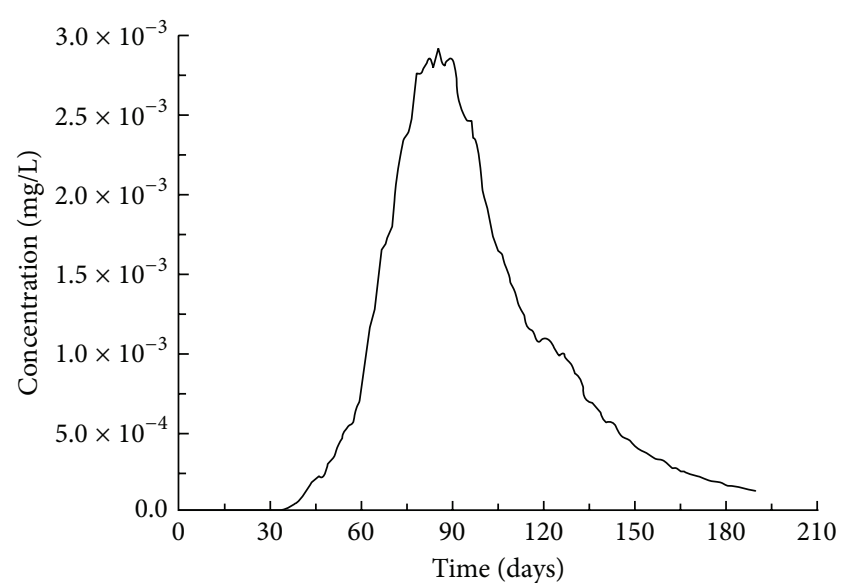

FIGURE 9: Concentration of cyanide in Taocha Dam area after accidental release of cyanide from the Dan River.

handling the toxic cyanide in the reservoir. However, shutting down the Taocha Dam has less effects on the cyanide concentration at the Hejiawan monitor site. Shutting down these two dams at the same time can reduce the peak concentration of cyanide at the Hejiawan monitor site and also postponed the peak concentration moving to the Hejiawan monitor site. However, the effects of shutting down these two dams were similar to only shutting down the Danjiangkou Dam. Thus, it is needless to shut down the Taocha Dam as soon as the accident happens.

Figure 10(b) shows that only shutting down the Danjiangkou Dam can obviously increase the cyanide concentration at the Taocha monitor site, and the starting time for the concentration increase was 50 days after the accident at the Yun City Bridge. Therefore, in order to protect the water quality for the S-N-M Project, it should increase the outflow rate in the Danjiangkou Dam when the cyanide approaches to the Danjiangkou Dam area, instead of shutting down it all the time.

3.4. Dam Cooperation Affects the Spread Characteristics of Cyanide from the Dan River. Figure 11 indicates that shutting down the dams has obviously affected the spread speed of cyanide in the reservoir. As Figure 11(a) shows that shutting down the Taocha Dam could obviously increase the cyanide concentration at the Hejiawan monitor site, but the concentration was very low. It indicated that the accidental release of cyanide from the Dan River brought no obvious effects on the Han River part in 90 days. As Figure 11(b) shows, shutting down the dams could obviously reduce the cyanide concentration at the Taocha monitor site. The effects of shutting down the Taocha Dam were more efficient than shutting down the Danjiangku Dam or these two dams together. Consequently, it is wise to shut down the Taocha Dam instead of the Danjiangkou Dam for reducing the spread speed of cyanide directing to the Taocha area and then further reducing the pollution risk of cyanide to the great S-N-M Project when accidental release of cyanide from the Dan River occurs.

\section{Conclusions}

In order to investigate the spread characteristics of toxic cyanide in the Danjiangkou Reservoir in the conditions of dam cooperation, a three-dimensional water quality model based on the Environment Fluid Dynamics Code (EFDC) was built and calibrated. The spread characteristics of cyanide in the reservoir were simulated based on eight scenarios related 


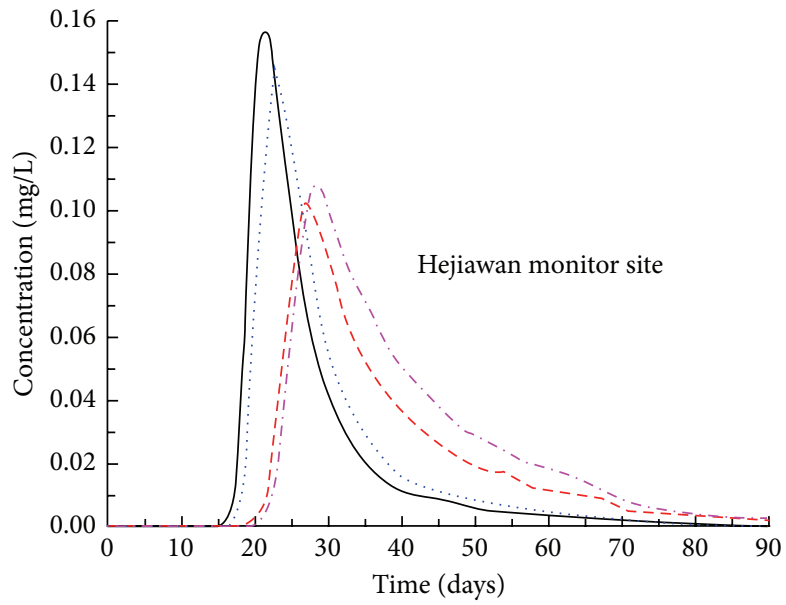

- Shut down no dam $\quad$ …. Shut down Taocha Dam - - Shut down Danjiangkou Dam . ..- Shut down the two dams

(a)

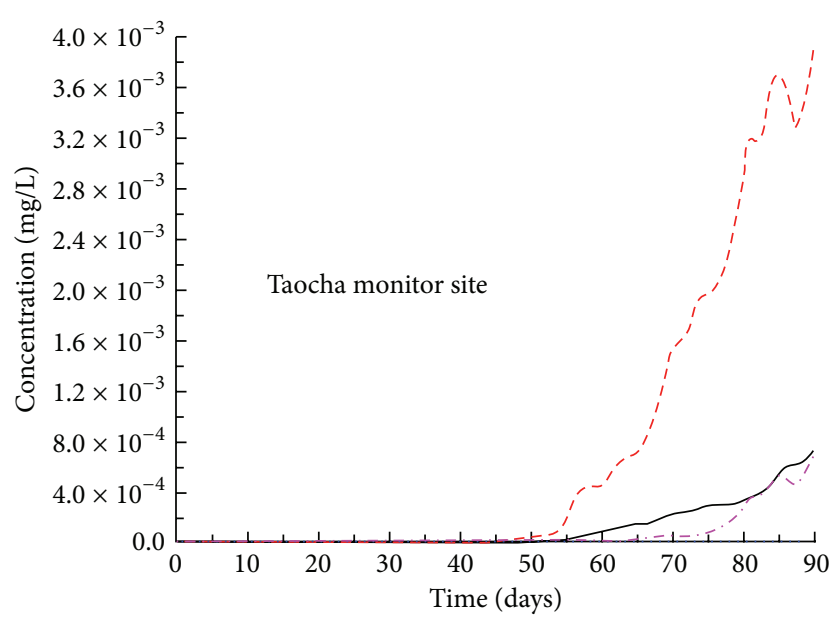

Shut down no dam Shut down Taocha Dam - - - Shut down Danjiangkou Dam . ... Shut down the two dams

(b)

Figure 10: Time series of cyanide concentration at Hejiawan monitor site (a) and Taocha monitor site (b) after accidental release of cyanide from the Yun City Bridge at the scenarios of shutting down dams.

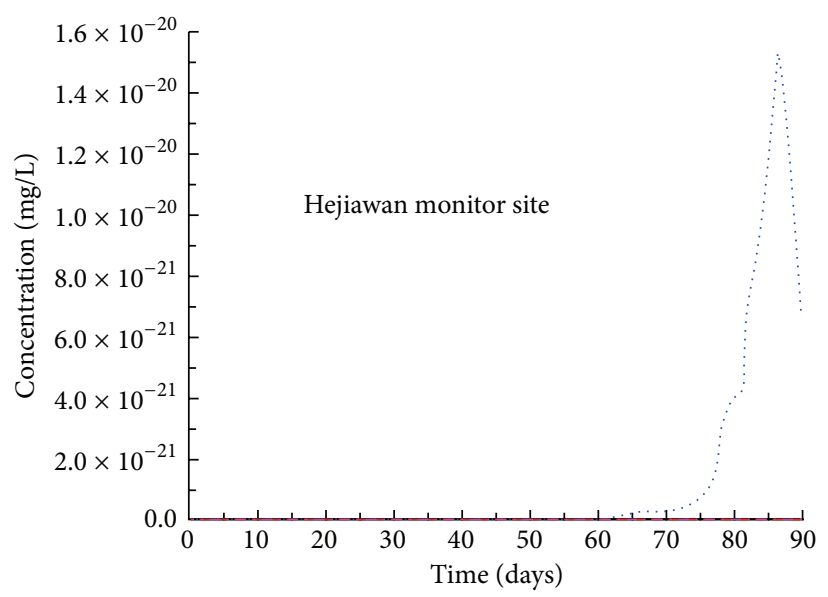

- Shut down no dam $\quad$...... Shut down Taocha Dam - - - Shut down Danjiangkou Dam ...- Shut down the two dams

(a)

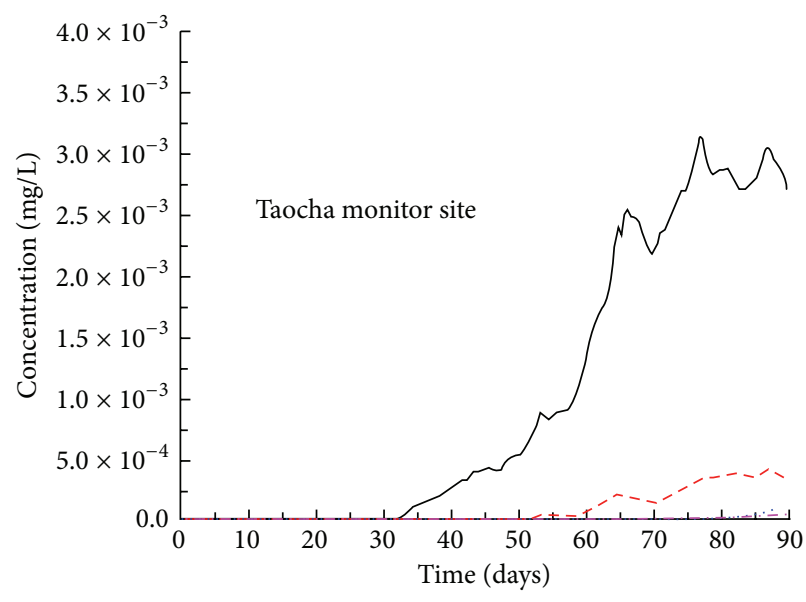

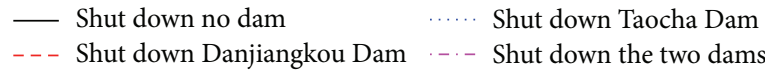

(b)

FiguRE 11: Time series of cyanide concentration at Hejiawan monitor site (a) and Taocha monitor site (b) after accidental release of cyanide from the Dan River at scenarios of shutting down dams.

to the two dams cooperation including the Danjiangkou Dam and the Taocha Dam. The following conclusions were reached: two separately accidental release of 2 tons of cyanide from two main tributaries of the reservoir would be no threat to the water quality for water diversion in the hydrological year of 2009; the increasing outflow in the Danjingkou Dam would avoid cyanide spreading to the Dan part of the reservoir when accidental release of cyanide from Han River occurs; it indicated that the Taocha dam but the Danjiangkou Dam should be shut down to reduce the concentration of cyanide in water intake mouth for water diversion when accidental release of cyanide from Dan River occurs.

The conclusions are derived from analysing a number of scenarios, but this problem could be also studied from a viewpoint of mathematical optimization trying to find the best strategy for dams operation when an accidental release of cyanide occurs. However, the mathematical optimization has to be based on a huge database of different strategy that needs much more computational effort to achieve, as each successful run of the model costs more than 20 hours. 
Anyhow, it is a good option when computational resource meets its requirement.

\section{Conflict of Interests}

The authors declare that there is no conflict of interests regarding the publication of this paper.

\section{Acknowledgments}

The financial support of the National Key Technology Research and Development Program (2011BAC12B02) and the Creative Research Groups of the National Natural Science Foundation of China (no. 51121003) is gratefully acknowledged.

\section{References}

[1] G. M. Van Dijk, E. C. L. Marteijn, and A. Schulte-WulwerLeidig, "Ecological rehabilitation of the River Rhine: plans, progress and perspectives," Regulated Rivers: Research o Management, vol. 11, no. 3-4, pp. 377-388, 1995.

[2] P. Soldán, M. Pavonič, J. Bouček, and J. Kokeš, "Baia mare accident-brief ecotoxicological report of Czech experts," Ecotoxicology and Environmental Safety, vol. 49, no. 3, pp. 255-261, 2001.

[3] Z. Li, M. Yang, D. Li et al., "Nitrobenzene biodegradation ability of microbial communities in water and sediments along the Songhua River after a nitrobenzene pollution event," Journal of Environmental Sciences, vol. 20, no. 7, pp. 778-786, 2008.

[4] A. Rebelo, I. Ferra, I. Gonçalves, and A. M. Marques, "A risk assessment model for water resources: releases of dangerous and hazardous substances," Journal of Environmental Management, vol. 140, pp. 51-59, 2014.

[5] M. F. Rahman, S. Peldszus, and W. B. Anderson, "Behaviour and fate of perfluoroalkyl and polyfluoroalkyl substances (PFASs) in drinking water treatment: a review," Water Research, vol. 50, pp. 318-340, 2014.

[6] P. H. Martin, E. J. LeBoeuf, E. B. Daniel, J. P. Dobbins, and M. D. Abkowitz, "Development of a GIS-based spill management information system," Journal of Hazardous Materials, vol. 112, no. 3, pp. 239-252, 2004.

[7] J. S. Camp, E. J. LeBoeuf, and M. D. Abkowitz, "Application of an enhanced spill management information system to inland waterways," Journal of Hazardous Materials, vol. 175, no. 1-3, pp. 583-592, 2010.

[8] Q. He, S. Peng, J. Zhai, and H. Xiao, "Development and application of a water pollution emergency response system for the Three Gorges Reservoir in the Yangtze River, China," Journal of Environmental Sciences, vol. 23, no. 4, pp. 595-600, 2011.

[9] J. Jiang, P. Wang, W.-S. Lung, L. Guo, and M. Li, "A GIS-based generic real-time risk assessment framework and decision tools for chemical spills in the river basin," Journal of Hazardous Materials, vol. 227-228, pp. 280-291, 2012.

[10] B. Zhang, Y. Qin, M. Huang et al., "SD-GIS-based temporalspatial simulation of water quality in sudden water pollution accidents," Computers and Geosciences, vol. 37, no. 7, pp. 874882, 2011.
[11] W. B. Samuels, D. E. Amstutz, R. Bahadur, and J. M. Pickus, "RiverSpill: a national application for drinking water protection," Journal of Hydraulic Engineering, vol. 132, no. 4, pp. 393403, 2006.

[12] M. Saadatpour and A. Afshar, "Multi objective simulation-optimization approach in pollution spill response management model in reservoirs," Water Resources Management, vol. 27, no. 6, pp. 1851-1865, 2013.

[13] J. Liang, "The harm of cyanide and its leakage accident counter measure," Guangdong Chemical Industry, vol. 39, no. 8, pp. 136137, 2012 (Chinese).

[14] J. M. Hamrick, "A Three-dimensional environmental fluid dynamics computer code: theoretical and computational aspects," Special Report 317, The College of William and Mary, Virginia Institute of Marine Science, 1992.

[15] Z.-G. Ji, G. Hu, J. Shen, and Y. Wan, "Three-dimensional modeling of hydrodynamic processes in the St. Lucie Estuary," Estuarine, Coastal and Shelf Science, vol. 73, no. 1-2, pp. 188-200, 2007.

[16] K. Park, H.-S. Jung, H.-S. Kim, and S.-M. Ahn, “Three-dimensional hydrodynamic-eutrophication model (HEM-3D): application to Kwang-Yang Bay, Korea," Marine Environmental Research, vol. 60, no. 2, pp. 171-193, 2005.

[17] Y. Liu, Y. Wang, H. Sheng et al., "Quantitative evaluation of lake eutrophication responses under alternative water diversion scenarios: a water quality modeling based statistical analysis approach," Science of the Total Environment, vol. 468-469, pp. 219-227, 2014.

[18] S. N. Chan, W. Thoe, and J. H. W. Lee, "Real-time forecasting of Hong Kong beach water quality by 3D deterministic model," Water Research, vol. 47, no. 4, pp. 1631-1647, 2013.

[19] C.-K. Kim and K. Park, "A modeling study of water and salt exchange for a micro-tidal, stratified northern Gulf of Mexico estuary," Journal of Marine Systems, vol. 96-97, pp. 103-115, 2012.

[20] Tetra Tech, The Environmental Fluid Dynamics Code Theory and Computation Volume 1: Hydrodynamics and Mass Transport, Tetra Tech, Fairfax, Va, USA, 2007.

[21] K. Park, A. Kuo, J. Shen, and J. A. Hamrick, "A threedimensional hydrodynamic-eutrophication model (HEM-3D): description of water quality and sediment process submodels (EFDC water quality model)," Special report no. 327 in applied marine science and ocean engineering, 1995, (rev. by Tetra Tech, Inc. 2000).

[22] Tetra Tech, The Environmental Fluid Dynamics Code Theory and Computation Volume 3: Water Quality Module, Tetra Tech, Fairfax, Va, USA, 2007.

[23] J. Zhao and K. Gao, "Technical analysis on the investigation and control plan of sodium cyanide leakage pollution," Environmental Protection of Chemical Industry, vol. 24, no. 5, pp. 355-357, 2004 (Chinese). 


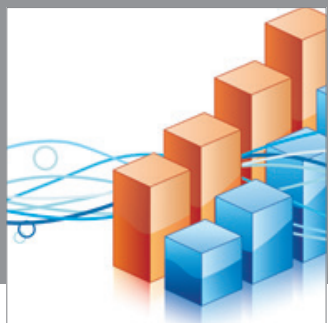

Advances in

Operations Research

mansans

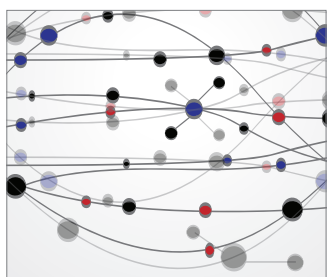

The Scientific World Journal
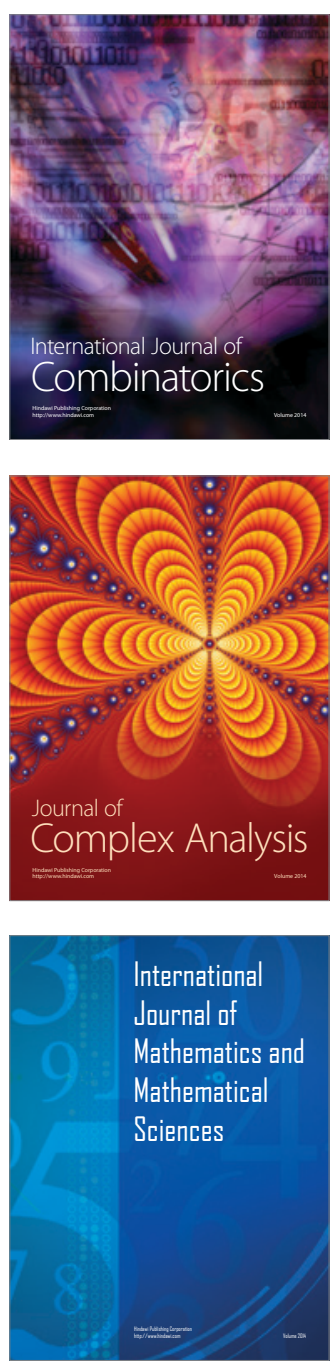
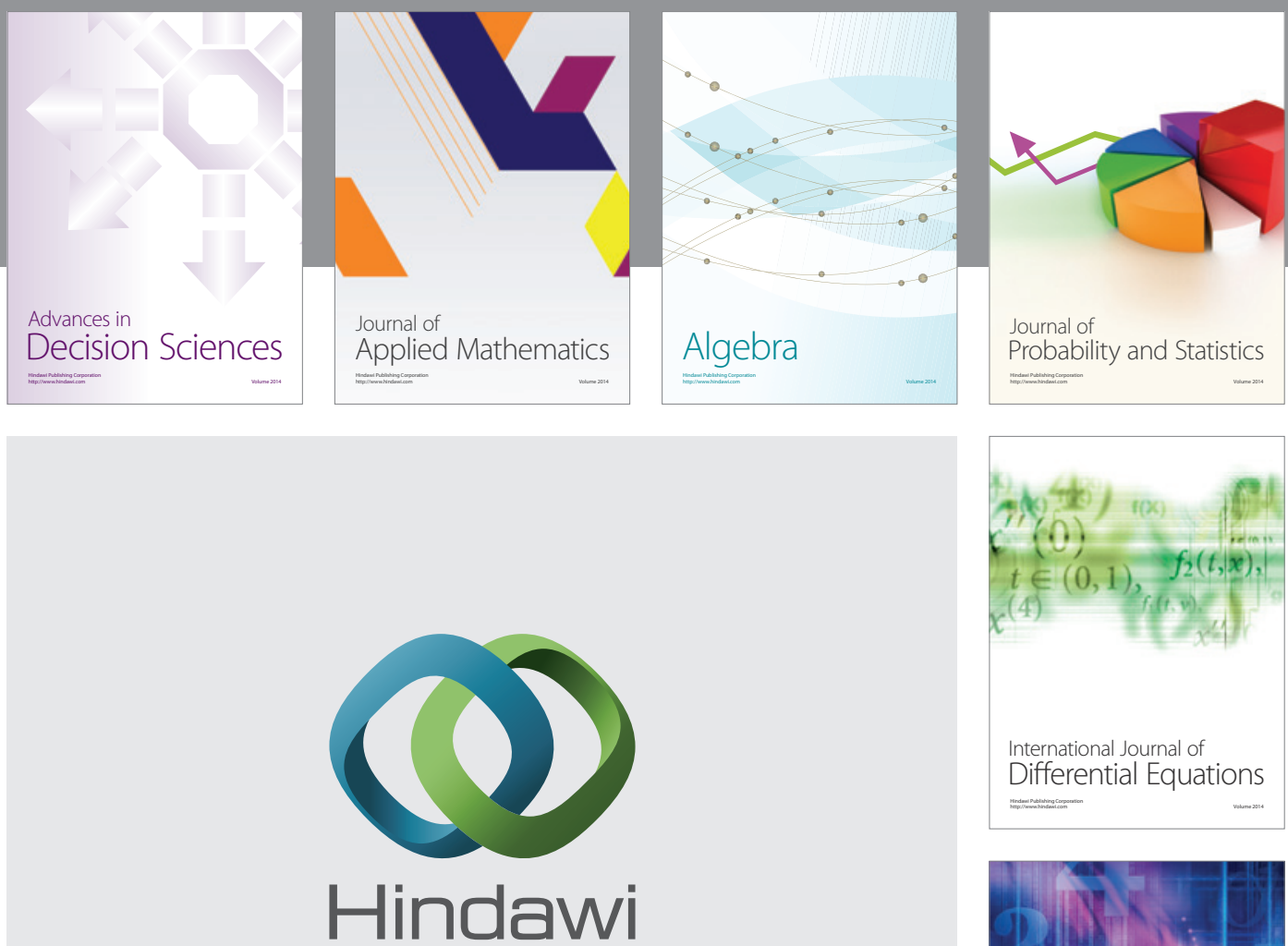

Submit your manuscripts at http://www.hindawi.com
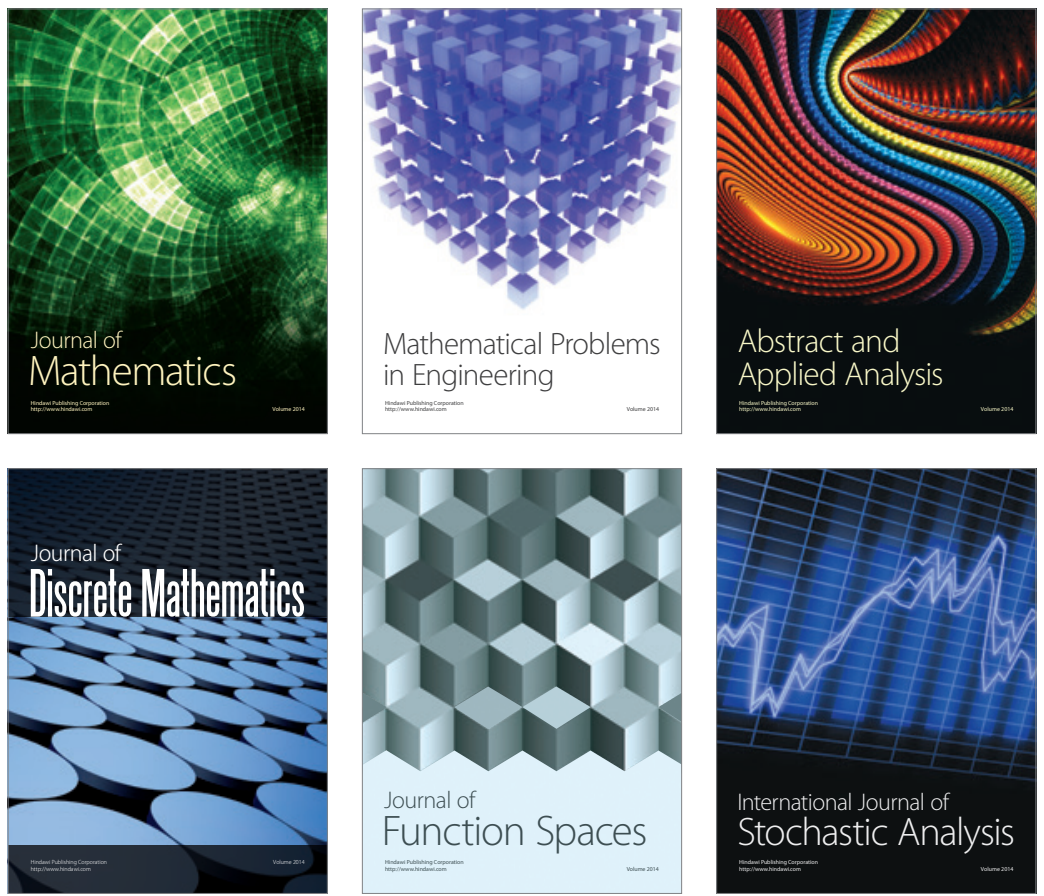

Journal of

Function Spaces

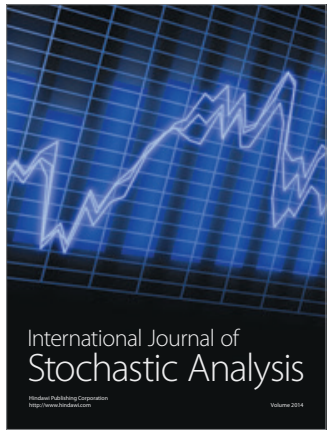

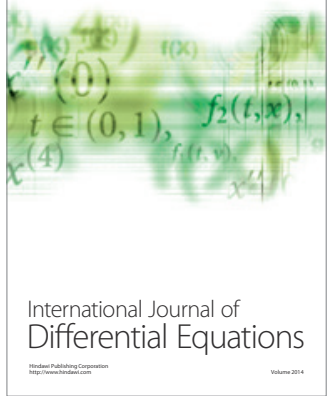
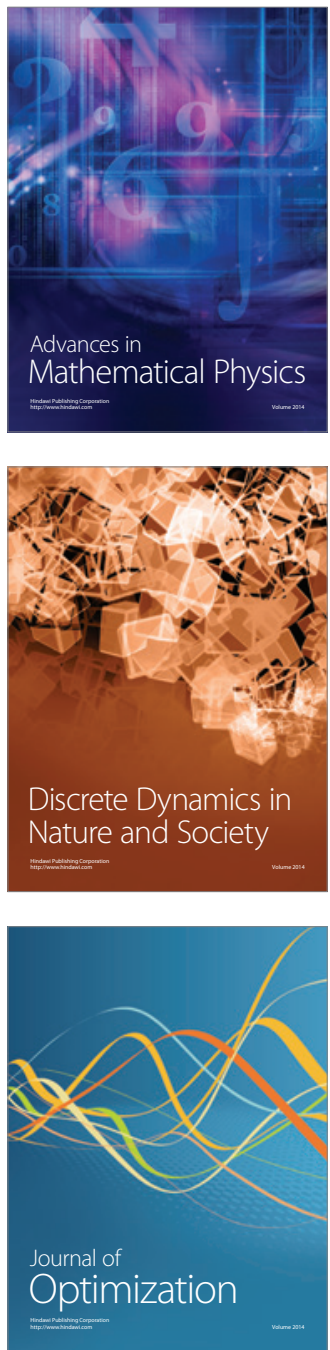